Wilfrid Laurier University

Scholars Commons @ Laurier

Kinesiology and Physical Education Faculty

Publications

Kinesiology and Physical Education

2010

\title{
Experiences of Burnout Among Adolescent Female Gymnasts: Three Case Studies
}

\author{
Nicole G. Dubuc \\ Laurentian University \\ Robert J. Schinke \\ Laurentian University \\ Mark A. Eys \\ Wilfrid Laurier University, meys@wlu.ca \\ Randy Battochio \\ Laurentian University \\ Leonard Zaichkowsky \\ Boston University
}

Follow this and additional works at: https://scholars.wlu.ca/kppe_faculty

\section{Recommended Citation}

Dubuc, Nicole G.; Schinke, Robert J.; Eys, Mark A.; Battochio, Randy; and Zaichkowsky, Leonard, "Experiences of Burnout Among Adolescent Female Gymnasts: Three Case Studies" (2010). Kinesiology and Physical Education Faculty Publications. 26.

https://scholars.wlu.ca/kppe_faculty/26

This Article is brought to you for free and open access by the Kinesiology and Physical Education at Scholars Commons@ @aurier. It has been accepted for inclusion in Kinesiology and Physical Education Faculty Publications by an authorized administrator of Scholars Commons @ Laurier. For more information, please contact scholarscommons@wlu.ca. 


\title{
Experiences of Burnout Among Adolescent Female Gymnasts: Three Case Studies
}

\author{
Nicole G. Dubuc, Robert J. Schinke, Mark A. Eys, \\ Randy Battochio \\ Laurentian University, Canada \\ Leonard Zaichkowsky \\ Boston University
}

\begin{abstract}
Within the current study, the process of adolescent burnout is considered in relation to perceived contributors, symptoms, consequences, and subsequently, effective and ineffective coping strategies. Through case studies, the researchers sought the burnout experiences of three competitive female gymnasts. Participants were selected based on scores obtained from Raedeke and Smith's (2001) Athlete Burnout Questionnaire. To gain a comprehensive understanding of the process, athlete data were considered in tandem with interviews from at least one parent and one coach. Transcribed data were segmented into meaning units, coded into a hierarchy of themes and verified by each respondent. Despite common trends among the participants, differences were also found in relation to symptoms, contributors, and the progression of the condition. Implications are provided for the athlete/parent/coach triad and also for sport psychologists.
\end{abstract}

Keywords: sport, youth, gymnastics, exhaustion

While striving to be the best in sport may fuel the dreams of many young athletes, the competitive pressures to succeed can be overwhelming (Gould \& Dieffenbach, 2002). Attempting to reach the pinnacle of their sport, athletes experience conflicting physical, emotional, and mental demands that can lead to sport burnout (Smith, 1986). Within amateur sport, athletes are often required to excel at a very young age. In addition to the training demands associated with elite sport, such as traveling, physical requirements, and injuries, adolescent athletes are required to balance academics with sports while trying to establish a sense of social belonging as well as a self-concept (Gould, Tuffey, Udry, \& Loehr, 1996a). Managing such demands may be especially challenging for adolescents, since their coping and problem solving skills are undeveloped as compared with adults, thus increasing the risk of maladaptive behavioral responses (Hampel \& Petermann, 2006).

Nicole G. Dubuc, Robert J. Schinke, Mark A. Eys, and Randy Battochio are with the School of Kinesiology at Laurentian University, Sudbury, Ontario,Canada. Leonard Zaichkowsky is with the Sport and Exercise Psychology Program at Boston University. 
Originally conceptualized in the 1970s, burnout was first introduced by Freudenberger (1975), who described the condition as exhaustion due to excessive demands, leading to ineffectiveness among human care professionals. A decade later, the issue of burnout emerged in the sport literature to understand the complexities associated with this process within an athletic context. Revising Maslach and Jackson's (1981) occupational definition, Raedeke (1997) specified that athlete burnout is most commonly characterized as a syndrome consisting of three distinct components: (a) emotional exhaustion, (b) sport devaluation, and (c) reduced personal accomplishment. Current research incorporating various sporting contexts reveals that the strains and antecedents for burnout are numerous, and the symptoms associated with each athlete can vary (e.g., Gustafsson, Kenttä, Hassmén, \& Lundqvist, 2007a; Lemyre, Treasure, \& Roberts, 2006). Despite the specific nature of sport, in many ways, the athletic burnout experience supports findings originating from the occupational literature and specifically, the 12 phases of burnout proposed by Freudenberger and North (1985). Freudenberger and North (1985) researched women's experiences of occupational burnout and highlighted several components, which are comparable to athlete burnout. According to these authors, the burnout process can be divided into 12 phases, which are not necessarily followed sequentially. The phases include (a) a compulsion to prove oneself, (b) working harder, (c) neglecting one's own needs, (d) displacement of conflicts, (e) revision of values, (f) denial of emerging problems, (g) withdrawal, (h) observable behavioral changes, (i) depersonalization, (j) inner emptiness, (k) depression, and (l) burnout syndrome.

Within the current study, the authors have sought to investigate burnout by examining the views of three adolescent female gymnasts through case studies. It should be noted that female gymnasts begin their sport relatively young, and they typically aspire to provincial and national standards in early (10-14 years) to middle adolescence (15-17 years; see Urdan \& Klein, 1998). Herein, each case reflects the views of an athlete, at least one parent, and at least one coach. The intent is to provide a comprehensive delineation of burnout as a process, employing the vantage point of each member. Consistencies and discrepancies are considered within and across the cases. Implications are proposed for researchers and practitioners interested in employing a triadic approach.

\section{Contributors to Burnout}

Within the previous literature, it has been revealed that athlete burnout can result from several sport related training factors, regarded here as contributors. Stemming from stress-based perspectives, an imbalance between the athlete's perceived demands and response capabilities can lead to high levels of stress associated with overload, boredom, and helplessness. In a high stress state, the risk of burnout is increased as athletes often develop maladaptive behaviors (Cresswell \& Eklund, 2006; Smith, 1986). Silva (1990) added that although training stress is necessary for improvement, when coupled with insufficient rest, conflict, excessive commitment, or minimal feedback, negative psychophysiological responses can occur.

Burnout has been linked to numerous sociological and personal contributors. For example, the social nature of organized sport at the elite levels (i.e., provincial/ national) can restrict life experiences due to sport demands causing reduced perceived control and autonomy, increasing the likelihood of burnout (Coakley, 1992). 
Supporting the sociological perspective, Schmidt and Stein (1991), Raedeke (1997), and Gustafsson, Kenttä, Hassmén, Lundqvist, and Durand-Bush (2007b) added that athletes with the above profile (e.g., reduced perceived control, reduced autonomy) may feel entrapped within their sporting environment, thus remaining involved despite low levels of enjoyment. In addition, Coakley suggested that burnout is especially likely among athletes who have devoted numerous hours to their sport from a young age and who are referenced solely in terms of their athletic identity (see also Gustafsson et al., 2007b). While parental support has been found to act as a buffer to many of the demands described above, the risk of burnout is increased if the athlete interprets parental involvement as a source of pressure.

\section{Symptoms of Burnout}

There are also a wide number of symptoms/manifestations of sport burnout. Most can be linked to the three indicators suggested by Raedeke (1997): (a) physical and emotional exhaustion, (b) reduced sense of personal accomplishment, and (c) sport devaluation. First, depleted physical and emotional energy resources have been linked to fatigue (Cresswell \& Eklund, 2006, 2007; Smith, 1986), lethargy (Cresswell \& Eklund, 2006; Goodger, Wolfenden, \& Lavallee, 2007; Gould et al., 1996b; Smith, 1986), mood disturbances (Goodger et al., 2007; Gustafsson, Kenttä, Hassmén, \& Johanssone, 2008), insomnia (Smith, 1986), illness (Goodger et al., 2007; Gould et al., 1997; Smith, 1986), and injury (Gould et al., 1996b). Reflecting such manifestations, athletes experience reduced levels of performance leading to inconsistencies and lack of improvement (Cresswell \& Eklund, 2006; Goodger et al., 1997; Smith, 1986), reduced confidence (Gould et al., 1997; Silva, 1990), a perceived cost and reward imbalance (Cresswell \& Eklund, 2006; Goodger et al., 2007), anxiety (Smith, 1986), frustration (Cresswell \& Eklund, 2006; Goodger et al., 2007; Gould et al., 2007; Gustaffson et al., 2008; Smith, 1986), irritability (Gould et al., 2007), and anger (Smith, 1986). Finally, as the sport environment becomes less valuable, athletes may lack the motivation and drive they once had (Cresswell \& Eklund, 2006; Gould et al., 1997; Gustafsson et al., 2008), find little enjoyment in sport and nonsport contexts (Cresswell \& Eklund, 2006), and have difficulty focusing (Cresswell \& Eklund, 2006; Goodger et al., 2007, Gould et al., 1997). For some, the consequences can be quite serious, as burnout has been linked to psychological disorders such as depression (Coakley, 1992; Smith, 1986) and eating disorders (Gustafsson et al., 2008). In many cases, athletes who suffer from burnout leave the sport prematurely (Goodger et al., 2007; Silva, 1990; Smith, 1986).

\section{Gaps Within the Literature}

While many of the findings above describe theoretical frameworks highlighting the burnout process along with possible contributors or associated symptoms, several aspects of burnout remain uncharted. While researchers have sought to highlight competitive adolescents' burnout experiences (i.e., Coakley, 1992; Gould et al., 1996a, 1996b, 1997; Gustafsson et al., 2007a), they have done so solely based on the athlete's perspective. Despite the high level of involvement of coaches and parents in the adolescent athlete's sport environment, a triadic approach (i.e., eliciting and 
comparing perceptions of burnout from athletes, parents, and coaches) has yet to be used. Through the proposed triadic approach, a shared understanding of the athlete's burnout status could ensue, leading to effective support in and through sport.

\section{Method}

The three case studies (forthcoming) will be presented as vignettes constructed to portray the respondents' experiences (Spalding \& Phillips, 2007). It should be noted that there are three types of vignettes, each with a distinct purpose. Snapshot vignettes provide participants, other researchers, or clients with the principle investigator's/practitioner's global description of the context, offered as a thirdhand account of what has been observed. Portrait vignettes are written as first-hand representations of the participant's/client's experiences, commonly framed with interview data woven inside the vignette. Portraits are meant to be written from the participant's/client's vantage. Finally, there are also composite vignettes, where case studies are built as hypothetical situations to exemplify a circumstance, leading to an educational discussion. The present vignettes combine the analytic aspect of snapshots with the supportive anecdotal evidence found in portraits. Creating these representations is intended to stimulate clinicians and researchers to reflect on the lived experiences of each gymnast and to interpret their own understanding of the burnout process. The case studies are also comprehensive, allowing researchers to capture the respondents unique and complex burnout stories. The methodology is comprised of six parts: (a) researcher assumptions, (b) participants, (c) question development, (d) data collection, (e) data analysis, and (f) trustworthiness.

\section{Researcher Assumptions}

Qualitative analysis requires some interpretation on the part of the researcher. Results are often subject to the researcher's cultural background, experiences, and biases. Schinke and da Costa (2000) suggested that sport psychology researchers must be aware of their own assumptions and biases to effectively report qualitative data. Based on experiences as an athlete and coach, the first author held several assumptions. Hence, before the start of the interview stage, she participated in a bracketing interview. Bracketing encourages the researcher to evaluate the research process and to interpret data through a different lens, one that may not have been considered without acknowledging how he or she is situated within the context. It also provides the opportunity to reflect on how best the respondents' voices can be accessed, interpreted, and presented (Rolls \& Relf, 2006). Similarly, the clinician benefits from the bracketing process by increasing the likelihood that the client's concerns are truly heard without interference from the clinician's personal views. The topics addressed included (a) personal sport background, (b) interest in sport burnout, and (c) question development and anticipated results for the proposed study. The bracketing interview was conducted with the second author, an experienced qualitative researcher.

\section{Participants}

Individuals representing three perspectives participated in the study: (a) athletes, (b) coaches, and (c) parents. The athletes were comprised of three current adoles- 
cent female gymnasts, each from a different club in Northern Ontario, Canada. The adolescents ranged in age from 11 to 16 years, and competed at a regional or provincial level for a minimum of 4 years. The four coaches held competitive experience coaching at a provincial level, and were the athletes' head coaches at the time of burnout. In one case, the coach had short-term experience working with the intended athlete participant. Thus, the athlete's previous coach also participated. Finally, the third vantage was comprised of at least one of each athlete's parents. In one case, both parents asked to participate, were equally involved in their daughter's sport involvement, and consequently were included in the study.

Participants were recruited once the project was approved through the PI's research ethics board. Recruitment was based upon Patton's (2002) purposive convenience sampling, whereby the participants were selected based on their potential to contribute rich and valuable information. Program directors from gymnastics clubs in Ontario, Canada were first contacted to access eligible respondents. Through information sessions and recruitment posters, interested participants who received parental consent were asked to complete the Athlete Burnout Questionnaire (Raedeke \& Smith, 2001) referring to their gymnastics experiences in the last two years. This 15-item self-report instrument comprises three 5-item subscales measuring (a) reduced sense of accomplishment (e.g., "It seems that no matter what I do, I don't perform as well as I should"), (b) devaluation (e.g., "I have negative feelings toward sport"), and (c) emotional and physical exhaustion (e.g., "I am exhausted by mental and physical demands of my sport"). Items are scored on a 5-point Likert scale ranging from 1 (almost never) to 5 (almost always). Acceptable internal consistency (alphas between 0.85 and 0.91 ), test-retest reliability, and construct validity have been previously reported (Raedeke \& Smith, 2001). Athletes who had a moderatehigh to high (i.e., 3.0-5.0) overall score, indicating previous burnout experiences, were interviewed. Next, coaches and parents of the selected athletes were contacted and subsequently interviewed.

\section{Question Development}

An initial version of questions for the interview guide was first presented to a panel consisting of one competitive adolescent gymnast as well as a parent and a coach of a competitive female gymnast. To select the panel, the researcher first contacted one of the gymnastics club's head coaches who agreed to participate and who suggested the name of a parent and a gymnast who were highly involved at the club. These individuals were later contacted by the researcher. The panel assisted in verifying and refining the questions and to clarify any topics that may have been ambiguous, extraneous, or absent from the interview guide. The goal was to develop questions that were understandable and relevant for the young gymnasts. The revised interview guide was then piloted with an adolescent gymnast. The pilot interview was audio-taped, transcribed, and subsequently reviewed by the first two authors. In addition, verbal feedback pertaining to the wording of questions and their relevance was sought from the pilot-participant and used to modify the interview guide. ${ }^{1}$

\section{Data Collection}

All respondents were initially asked to fill out a short demographic questionnaire. The athletes were asked to summarize their gymnastics background, while parents 
and coaches were asked to provide supplemental information concerning their involvement in the athlete's gymnastics experiences. Next, each respondent participated in a three part semistructured interview. The interview consisted mostly of open-ended questions and lasted approximately $60 \mathrm{~min}$. During the first part of the interview, the researcher introduced the research topic and purpose. The athlete participants were asked to share previous sport experiences and challenges they faced and how the aforementioned may have contributed to their burnout experience. The final section pertained to each gymnast's views of their respective triad's involvement (i.e., parents, coaches, teammates) and of how she believed the experience was understood from the varying vantages. Slight modifications were made to the interview guides for parents and coaches to capture their perspectives of their respective gymnast's sport experiences. Discussions with participants included the use of probes to seek a thicker description (Patton, 2002). Included were detail probes (e.g., "Why did you feel like you were missing out on time with your friends?"), elaboration probes (e.g., "Can you tell me more about how you were feeling when you knew you had to increase your training for an upcoming competition?"), and clarification probes (e.g., "You mentioned that your teammates were supportive, what do you mean by that?").

\section{Data Analysis}

Following each interview, the data were transcribed verbatim and segmented into "meaning units" representing a single thought or idea (Tesch, 1990). The first author developed a coding system into categories and subcategories using the meaning units derived from the three triad's interviews. Next, coded interviews were sent back to participants to allow for changes and clarifications. The coding scheme and associated meaning units were also verified by a graduate student familiar with qualitative data analysis to achieve consensus. The first and second authors also met throughout the analysis to discuss the organization and representation of themes. Once all interviews were analyzed, the respondents took part in a follow-up focus group interview (Gauthier, Schinke, \& Pickard, 2006; Morgan, 1997) involving the athlete, the parent, and the coach. The focus group interviews consisted of unstructured discussions pertaining to the themes contained in the results table that were presented to each triad member. Although comments from each follow-up interview were transcribed and considered for integration into the initial results, only one suggestion was provided by several members. The theme "looking for attention" was removed as a burnout symptom, as several respondents shared that it was not indicative of the gymnast's negative experience.

Two different approaches were taken to analyze and present the results. First, individual cases were discussed through vignettes written in narrative form constructed to portray both the respondents' character and experiences (Spalding $\&$ Phillips, 2007). The vignettes are constructed sketches relaying experiences communicated by respondents, which aim to provide clear and concise profiles for readers. To maintain confidentiality and protect the respondents' identities, pseudonyms were used to replace the names of the participants and all other parties (Meehan, Bull, Wood, \& James, 2004). The profiles were used to share each athlete's story. Themes and subthemes are discussed individually and presented in a table to highlight similarities and differences (see Table 1). 
Table 1 Athletes', Parents', and Coaches' Perceptions of the Burnout Experience

\begin{tabular}{|c|c|c|c|c|}
\hline Themes and Subthemes & Athlete MUs & $\begin{array}{l}\text { Parent } \\
\text { MUs }\end{array}$ & $\begin{array}{l}\text { Coach } \\
\text { MUs }\end{array}$ & Sum \\
\hline \multicolumn{5}{|l|}{ Influences } \\
\hline \multicolumn{5}{|l|}{ Parents } \\
\hline Understanding & $1 / 3 / 0(4)^{\mathrm{a}}$ & $5 / 1 / 1(7)$ & $1 / 0 / 0(1)$ & 12 \\
\hline Encouragement & $2 / 0 / 3(5)$ & 0/0/1 (1) & $0 / 0 / 2(2)$ & 8 \\
\hline Transportation & $1 / 0 / 0(1)$ & 2/0/1 (3) & 0/0/0 (0) & 4 \\
\hline Expectations & $2 / 0 / 1(3)$ & $8 / 1 / 0(9)$ & $4 / 0 / 0(4)$ & 16 \\
\hline Motivation & $1 / 0 / 0(1)$ & $1 / 0 / 0(1)$ & $0 / 2 / 1(3)$ & 4 \\
\hline \multicolumn{5}{|l|}{ Friends } \\
\hline Hanging out & $3 / 0 / 0(3)$ & $0 / 1 / 0(1)$ & 0/0/0 (0) & 4 \\
\hline \multicolumn{5}{|l|}{ Teammates } \\
\hline Motivation & $0 / 1 / 2(3)$ & $0 / 1 / 1(2)$ & $1 / 0 / 0(1)$ & 6 \\
\hline \multicolumn{5}{|l|}{ Gym club } \\
\hline Like a family & $0 / 0 / 2(2)$ & $0 / 0 / 1(1)$ & $0 / 0 / 0$ & 3 \\
\hline \multicolumn{4}{|l|}{ Teachers and principals } & 4 \\
\hline \multicolumn{5}{|l|}{ Coach } \\
\hline Encouraging & $2 / 1 / 2(5)$ & 0/0/1 (1) & $0 / 0 / 0(0)$ & 6 \\
\hline Understanding & $1 / 3 / 2(6)$ & $0 / 0 / 0(0)$ & $0 / 2 / 1(3)$ & 9 \\
\hline Caring & $0 / 1 / 0(1)$ & $0 / 0 / 0(0)$ & $0 / 5 / 0(5)$ & 6 \\
\hline Motivation & $0 / 0 / 4(4)$ & 0/0/1 (1) & $0 / 0 / 2(2)$ & 7 \\
\hline How they coach & $0 / 0 / 5(5)$ & $7 / 0 / 1(8)$ & $1 / 0 / 0(1)$ & 14 \\
\hline Unhappy with coach & $0 / 3 / 4(7)$ & $0 / 0 / 0(0)$ & $0 / 0 / 0(0)$ & 7 \\
\hline \multicolumn{5}{|l|}{ Challenges } \\
\hline Scared to get hurt & $0 / 3 / 1(4)$ & $0 / 0 / 0(0)$ & $0 / 1 / 0(1)$ & 5 \\
\hline Physical requirements & $0 / 0 / 0(0)$ & $0 / 0 / 0(0)$ & $0 / 0 / 3(3)$ & 3 \\
\hline \multicolumn{5}{|l|}{ Making sacrifices } \\
\hline Schedule conflicts & $3 / 5 / 3(11)$ & $10 / 2 / 6(18)$ & $3 / 1 / 0(4)$ & 33 \\
\hline Making time for friends & $4 / 1 / 3(8)$ & $1 / 3 / 1(5)$ & $0 / 0 / 2(2)$ & 15 \\
\hline Balancing school and gym & $1 / 1 / 2(4)$ & $2 / 3 / 2(7)$ & $1 / 1 / 4(6)$ & 17 \\
\hline Being hurt & 1/4/1 (6) & $0 / 4 / 0(4)$ & $0 / 4 / 0(4)$ & 14 \\
\hline \multicolumn{5}{|l|}{ Perceived contributors } \\
\hline Overtraining & 2/0/0 (2) & 0/0/0 (0) & 0/0/0 (0) & 2 \\
\hline Poor time management & $0 / 0 / 0(0)$ & $0 / 0 / 0(0)$ & $0 / 0 / 1(1)$ & 1 \\
\hline Failure & $0 / 0 / 0(0)$ & $0 / 1 / 0(1)$ & $0 / 1 / 0(1)$ & 2 \\
\hline Perfectionism & $0 / 0 / 0(0)$ & $0 / 1 / 2(3)$ & $0 / 0 / 0(0)$ & 3 \\
\hline \multicolumn{5}{|l|}{ Symptoms } \\
\hline Can't concentrate & $1 / 1 / 3(5)$ & $0 / 0 / 0(0)$ & 8/0/1 (9) & 14 \\
\hline Eating problems & $0 / 0 / 0(0)$ & $0 / 0 / 2(2)$ & $0 / 0 / 2(2)$ & 4 \\
\hline Making excuses & $0 / 0 / 0(0)$ & $0 / 0 / 3(3)$ & $0 / 1 / 1(2)$ & 5 \\
\hline Frustration & 4/0/5 (9) & $0 / 3 / 0(3)$ & 0/3/0 (3) & 15 \\
\hline Stressed out & $0 / 6 / 0(6)$ & $0 / 2 / 2(4)$ & 0/0/1 (1) & 11 \\
\hline Grouchiness & $0 / 2 / 1(3)$ & $0 / 0 / 0(0)$ & $0 / 0 / 0(0)$ & 3 \\
\hline Tired & $12 / 5 / 0(17)$ & $2 / 0 / 0(2)$ & $5 / 0 / 6(11)$ & 30 \\
\hline
\end{tabular}


Table 1 (continued)

\begin{tabular}{lcccc}
\hline Themes and Subthemes & Athlete MUs & $\begin{array}{c}\text { Parent } \\
\text { MUs }\end{array}$ & $\begin{array}{c}\text { Coach } \\
\text { MUs }\end{array}$ & Sum \\
\hline Symptoms, continued & & & & \\
Problems sleeping & $2 / 0 / 0(2)$ & $0 / 0 / 0(0)$ & $0 / 0 / 0(0)$ & 2 \\
Disappointment & $2 / 0 / 5(7)$ & $0 / 2 / 0(2)$ & $0 / 0 / 0(0)$ & 9 \\
Lack of drive & $3 / 5 / 12(20)$ & $4 / 7 / 1(12)$ & $4 / 2 / 4(10)$ & 42 \\
Loneliness & $6 / 0 / 0(6)$ & $0 / 0 / 0(0)$ & $0 / 0 / 0(0)$ & 6 \\
Low self-esteem & $0 / 1 / 1(2)$ & $0 / 1 / 0(1)$ & $0 / 1 / 0(1)$ & 4 \\
Mild depression & $0 / 0 / 0(0)$ & $0 / 0 / 0(0)$ & $0 / 1 / 0(1)$ & 1 \\
Doing worse at the gym & $2 / 1 / 0(3)$ & $0 / 0 / 0(0)$ & $1 / 1 / 0(2)$ & 5 \\
Doing worse at school & $0 / 0 / 0(0)$ & $1 / 0 / 0(1)$ & $0 / 0 / 0(0)$ & 1 \\
Missing practices & $0 / 2 / 0(2)$ & $1 / 2 / 0(3)$ & $0 / 1 / 0(1)$ & 6 \\
Responding to the struggles & & & & \\
Overcoming obstacles & $3 / 1 / 0(4)$ & $0 / 0 / 0(0)$ & $2 / 0 / 0(2)$ & 6 \\
Looking for help & $0 / 0 / 1(1)$ & $0 / 0 / 1(1)$ & $0 / 0 / 0(0)$ & 2 \\
Finding a balance & $2 / 6 / 1(9)$ & $1 / 5 / 1(7)$ & $1 / 2 / 1(4)$ & 20 \\
Rest/recuperation & $1 / 2 / 0(3)$ & $0 / 1 / 0(1)$ & $2 / 1 / 1(4)$ & 8 \\
\hline
\end{tabular}

Note. ${ }^{\text {a }}$ The meaning units in each category are presented by triad $1 /$ triad $2 /$ triad 3 (total).

\section{Trustworthiness}

To ensure trustworthiness of the study, the researcher adhered to three of Maxwell's (2002) proposed validity types, which are said to increase the project's rigor: (a) descriptive validity, (b) theoretical validity, and (c) interpretive validity. Descriptive validity, described as intersubject agreement of observable specific events and situations (Maxwell, 2002), was enhanced by audio-recording each interview and using these recordings to confirm accurate transcription. To further support the descriptive validity, due to the first author's limited experience in competitive gymnastics, an expert panel was consulted to provide feedback regarding question refinement of the preliminary interview guide. According to Maxwell, theoretical validity refers to the theoretical constructions of specific concepts applied to the phenomenon and the hypothesized relationships linking these concepts. As such, the researcher coded every interview into categories and subcategories and consulted the remaining authors to review the classification and obtain consensus regarding proposed categories. Finally, the respondents were sent copies of their transcripts and coded interviews to encourage refinements and increase interpretive validity, in other words, to portray what the words, events, and behaviors meant to the respondents.

\section{Results Part A: Vignettes}

Through the current article, we have delineated the process of burnout with three adolescent female gymnasts through the eyes of the athlete, the parent, and the coach. The present section offers vignettes of each case. These profiles highlight the unique experiences of each gymnast, thus providing clinicians with the opportunity to explore the diverse dimensions of the burnout process. 


\section{Case Study 1: Stephanie}

Stephanie was 11 years old, had been participating in gymnastics for 9 years, and had spent the last 4 years competing at a provincial level. She had trained an average of $15 \mathrm{hr}$ per week for 11.5 months out of each year. Although she improved during the previous 2 years, she had recently felt fatigued. She admitted that fatigue contributed to a lack of drive, which in turn hindered performance. New challenges Stephanie associated with her competitive environment were contributing to the difficulties she was experiencing. Balancing school and gymnastics had become a challenge. In fact, recently, she felt that most of her energy was being devoted to gymnastics rather than school. Her coaches confirmed that because of her intense training schedule, little time was left for homework. Her dad explained that she has had to miss birthday parties, among other activities with school friends. At the gym, despite opportunities for socializing, Stephanie felt lonely. She added that she felt lonesome particularly at competitions, since she was alone with her coach. Despite her sentiments, her parents and coaches agreed that Stephanie coped well with her challenges of maintaining a balanced lifestyle. Both adult sources believed that the challenge was an opportunity for Stephanie to learn how to organize competing demands and make the necessary choices that would lead to athletic success.

Despite the coping skills described above, Stephanie felt overwhelmed. Feeling as though she had several time constraints, she expressed the need to have a "social life." She had been falling asleep in class and admitted to lacking daily motivation. She reported that she was waking up several times at night and felt that this was related to her gymnastics training. Recently, while struggling through back pain, her gymnastics performance began to decline. Stephanie's parents and coach acknowledged her fatigue and occasional lack of drive. According to Stephanie's mother, this lack of drive also extended to her daughter's academic efforts as Stephanie had recently started hiding school books and blaming gymnastics for unfinished homework.

At the gym, Stephanie admitted becoming frustrated when not successfully performing a skill and that she had been irritable with others. Interestingly, one of her coaches commented that she was not hard on herself and felt that Stephanie lacked intensity and focus. Stephanie's symptoms were consistent with those typically present during the earlier stages of burnout. If unresolved, however, Stephanie predicted that following her current state of fatigue, her performance would decrease, leaving her "grumpy" and unmotivated. Consequently, she thought she would have little choice but to quit gymnastics.

\section{Case Study 2: Kara}

Kara was a 15-year-old high school student with 11 years of gymnastics experience. During the last 5 years competing at a provincial level, she trained an average of $13.5 \mathrm{hr}$ per week for 11 months of the year. Kara was also involved in extra sports, social activities, and employment, but according to her mother, "gymnastics is her life." Although she attempted to coordinate a busy schedule, Kara felt overwhelmed and fell in and out of several burnout episodes in the past couple of years. Due to the long-standing presence of competitive gymnastics in her life, Kara felt highly attached to the sport, and, despite taking time away for recovery, she always felt persuaded to return to the sport. 
Although described by her mother and her coach as a motivated and determined gymnast, Kara had encountered several challenges that led to sport setbacks. First, she struggled to adapt to five different coaches, some of whom she thought were negative and degrading. As the training intensity increased, however, one of her biggest struggles was practicing through several injuries. Consequently, Kara and her coach explained that she developed an irrational fear of injury, causing her to relearn skills and minimizing her progression. Her attempt to balance several extracurricular activities and advanced school courses also posed a challenge. Despite the importance Kara attributed to maintaining a social life, she thought that such a priority was difficult to maintain. Kara's coach added that her struggle to find a balance was due to a desire to excel in all domains.

To manage her busy schedule, Kara and her mother emphasized the importance of communication and agreed that school took precedence, as she sometimes opted to come to the gym late or take a night off. At times, when overwhelmed or injured, she took some time away from the sport to recuperate. On several occasions in the last two years, however, Kara began showing signs of burnout. Kara admitted that she was irritable and lacked focus because she "had too much going on." Despite Kara's frustrations with injuries, her mother believed that one of Stephanie's biggest frustrations stemmed from the fact that she was performing at the same level with little advancement for a long period of time, which according to all three triad members, also negatively impacted her self-esteem. Her mother added that such frustration led to a decrease in Kara's motivation to attend practice.

Kara recalled a time toward the end of the previous school year when she was "exhausted." Contrastingly, her mother did not recall having seen Kara fatigued, describing her as a "high energy person." Eventually, according to her coach, Kara's symptoms filtered outside the gym, as she became apathetic. In addition, according to her coach, she and some teammates became concerned that Kara was showing early signs of anorexia, as she began depriving herself from eating regular meals and became overly concerned about her weight. Although Kara's disordered eating was reportedly resolved without any medical or professional assistance, lasting only a few months and failing to cause long-term health risks, her coach thought that her problem stemmed from an unmet need for control and attention. Kara's coach and her mother thought that she became hard on herself, although they thought she rarely shared such feelings and was generally reserved and withdrawn. To compensate for Kara's disappointment, they suggested that she used injuries as a justification for unmet goals. Kara, her mother, and her coach thought that stress resulting from a lack of time and a buildup of activities contributed to her burnout. Her mother and coach, however, emphasized that it was, in fact, her perfectionism that triggered burnout.

\section{Case Study 3: Danielle}

At the time of the interview, Danielle was a 16-year-old high school student who attended various regional meets for 7 of the 9 years she was involved in gymnastics. Danielle was in training for 8 months per year, practicing $11 \mathrm{hr}$ per week on average. Despite her recent improvements and her new found sense of enjoyment, Danielle remembered a time when she was ready to "give up" because gymnastics became a source of frustration and discouragement. 
Although Danielle's coach described her training as moderately intense, Danielle perceived having faced several challenges as a gymnast. First, after spending a few years away from competitive gymnastics, she returned in the midst of pubertal development and found it difficult to adapt to the physical changes associated with this growth period. In addition, Danielle and her coach thought that distractions at the gym were a continuous challenge. Next, in addition to training through injuries (e.g., shin splints), she also struggled psychologically to overcome the fear of injury. All three triad members noted that it became increasingly difficult for Danielle to maintain a proper balance between school, friends, and gymnastics. Her mother thought that, sometimes, she had too much on her plate. As a result, aside from missing occasional practices to "catch up" on homework, the coach thought that Danielle came to practice worried and unfocused.

Danielle recalled a season 2 years ago when she felt frustrated and overwhelmed by these challenges. She explained that she had begun the season with "really high expectations but was not able to live up to them," causing a decrease in motivation and in self-esteem. Danielle added that she felt sad and disappointed in herself. From a different perspective, her coach commented that her lack of drive seemed to be related to high levels of fatigue and explained that Danielle would resort to socializing and minimal training effort when she was tired. According to Danielle, some of her coaches were also contributing to her burnout. She thought that they paid little attention to her and provided her with minimal encouragement. Nevertheless, the on-going support and encouragement from Danielle's mother was recognized by Danielle and her coach. In addition, Danielle explained that despite having contemplated withdrawing from gymnastics during difficult times, she felt as though her teammates and coaches were "like a family" and that being part of the group was important enough for her to continue participating.

Despite describing the presence of early burnout indicators, Danielle did not claim to have reached the later stages of burnout. Interestingly, her mother did not recognize Danielle's past burnout experience and was surprised that she had shown signs of burnout, claiming that Danielle did not take gymnastics very seriously. While Danielle's coach acknowledged her athlete's past fatigue, lack of motivation, and thoughts of leaving gymnastics, she thought that she had not seen Danielle "get to a point of full out burnout." This past season, Danielle coped with challenges by hiring a tutor to help her stay on top of her schoolwork. In addition, being one of the veterans at the gym, she had taken it upon herself to have a positive attitude, stay focused, and set an example for the younger gymnasts. Finally, at times when her schedule became overly demanding, Danielle took time to recuperate. Her coach explained that following such breaks, Danielle's demeanor improved drastically. Overall, Danielle's frustration and consequent lack of interest and focus typified her burnout experience.

\section{Results Part B: Thematic Analysis}

The participants' reflections of the burnout process are now highlighted by trends from the data. Topics deriving from a content analysis were (a) how parents, coaches, and peers are involved; (b) perceived challenges; (c) burnout symptoms; (d) coping strategies; and (e) the burnout process (see Table 1). 


\section{Similarities}

A few similarities across respondent groups were identified. First, maintaining a balance between gymnastics and other commitments such as school, friends, and extracurricular activities, was a challenge noted by all respondent groups. As a result, finding the proper balance and prioritizing were the most common coping strategies proposed. In addition, the athletes thought that their sport was physically demanding, and consequently, being injured, and then training through injuries were common obstacles throughout the gymnasts' experiences. Each member of all three triads also noted that the gymnasts lacked motivation during the burnout period identified by the gymnasts; however, the loss of motivation was acknowledged most frequently by the gymnasts. Finally, all respondents agreed that their inability to balance gymnastics with other commitments such as school, friends, and extracurricular activities, was a significant challenge.

\section{Differences}

Differences across triads were also identified. A fear of injury among the gymnasts was often overlooked by the coaches and parents. While the gymnasts thought it had become increasingly difficult to make time for friends, parents and coaches were unaware of this struggle, indicating that the athletes socialized while at their gymnastics club. Most noteworthy, however, were differences related to burnout symptoms. For example, while irritability, difficulty sleeping, and feeling lonely were linked to Stephanie's burnout experience, these symptoms did not emerge from the interviews with Kara and Danielle's triads. On the other hand, feeling "stressed out" was noted as characteristic of both Kara and Danielle's experiences, but such tension was not expressed in relation to Stephanie's burnout. Next, while all of the athletes recalled being tired and exhausted each athlete's fatigue was less obvious to their coaches and parents. Similarly, while two of the gymnasts revealed having been disappointed in their performances, the theme was not identified by the coaches and was only discussed by one parent, who interestingly was not the parent of either disappointed gymnast. Despite the parents' and coaches' abilities to recognize burnout, a few coaches and most parents did not associate burnout with their gymnast's past experiences. Although the parents and coaches may have been able to recognize some of burnout's later stage consequences (e.g., a lack of motivation, loss of interest), they were less likely to detect early warning signs such as fatigue, frustration, and disappointment.

\section{Discussion}

From the current study, we have outlined the burnout episodes of three adolescent female gymnasts. Few respondents from the current study were able to identify a clear progression to burnout. The respondents did, however, articulate that fatigue, frustration, and a decrease in motivation were early indicators. The development of subsequent burnout symptoms varied based on the athletes' unique experiences. What follows is a discussion of emergent results in relation to the extant literature. 


\section{Burnout Symptoms}

Results from the current study did reaffirm and support some previous research findings pertaining to potential sport burnout symptoms. First, from a broader perspective, all three of the overarching burnout characteristics proposed by Raedeke (1997; i.e., physical and emotional exhaustion, sport devaluation, decreased sense of personal accomplishment) were found as part of the gymnasts' experiences. Much like the athletes from past studies (i.e., Cresswell \& Eklund, 2006, 2007; Gould et al., 1996a, 1996b, 1997; Raedeke, Lunney, \& Venables, 2002; Smith, 1986), it was frequently identified by the gymnasts and their coaches that the gymnasts were tired throughout their burnout episodes. Though perhaps not an insomniac, one athlete did share that she was having difficulty sleeping through the night, thus increasing her fatigue. Mirroring the burnout experiences described in Coakley's (1992) and Gould et al.'s (1996a, 1996b) work, it was also noted that the gymnasts herein admitted to being stressed, irritable, and frustrated with their gymnastics. For two of the athletes, staying focused and concentrating on their gymnastics throughout practices became more difficult. Supporting the views of Gould et al. (1996b), all three athlete participants discussed their struggles with injuries. In addition, as previously noted by Raedeke et al., (2002), Smith (1986), and Silva (1990), the gymnasts' performances began to plateau as they failed to perform required skills. With time, a decline in two of the athletes' performances was noted by the athletes and their respective coaches. Disappointed in their performances and in themselves, two gymnasts also expressed having low self-esteem.

A few burnout symptoms presented in past studies were not found in this project. First, despite feeling unmotivated in regard to their training, the respondents did not indicate an increased fear of competition, as was proposed by Hollander and Meyers (1995). When the training seemed to become redundant, the athletes continued to look forward to competitions. As the athletes' performance expectations were not met at competitions, however, their excitement and anticipation diminished, and the gymnasts became more apathetic than fearful. In addition, contrary to findings from Coakley (1992), Gould et al. (1996a, 1997), and Smith (1986), the gymnasts did not show any indication of being angry despite being frustrated. This is perhaps because they felt overwhelmed with disappointment in themselves and lacked the energy and motivation to channel their frustrations toward angry responses. The unsupported findings may not have emerged in the current study for a few reasons. First, unlike many of the studies pertaining to athletic burnout (i.e., Gould et al., 1996a; Gustafsson et al., 2007a; Gustafsson et al., 2008), the gymnasts taking part in this project did not have extreme burnout scores, nor did they leave their sport. Consequently, symptoms associated with later stages of burnout may not have emerged. In addition, some of the new symptoms and unsupported differences may result from the inclusion of the parents' and coaches' perspectives offering a vantage often uncharted.

Within the current study, there were also symptoms unidentified in previous literature. It was reported that during the burnout episodes, the athletes started making excuses for poor performances. One parent thought her daughter was using injuries as a "crutch" to justify a lack of improvement or unachieved goals. For another gymnast, the lack of drive typically associated with gymnastics transferred into her academic life, as her parents noticed a decline in her school work ethic. As 
balancing school and gymnastics became more difficult, the gymnasts attending high school also frequently mentioned feeling "stressed." Although the gymnasts did not experience extreme levels of burnout, the caring and encouragement of parents and most recent coaches helped two of the gymnasts overcome their condition. Such findings suggest that burnout may not necessarily end in the withdrawal from the sport activity. With sufficient social support and the implementation of effective coping, some athletes may avoid entering the final phase of burnout and remain active in sport. The presence of emerging symptoms from the current study suggests that there are nuances within the burnout condition than can be unique to specific populations and individuals.

\section{Burnout Contributors}

In considering possible contributors to burnout, the current study supported several findings from previous literature. As suggested within Smith's cognitive affective burnout model (1986), despite the buffering effect of social support, the contextual demands the gymnasts experienced were either conflicting or surpassed available resources, leading to overload. In addition, two of the gymnasts expressed feeling little reward for the sacrifices they were making and the time they were committing to sport; however, the athletes were also conflicted, as they committed to gymnastics so early in life and felt as though they may be "lost" without gymnastics (Coakley, 1992; Gustafsson et al., 2007b). In fact, it was this sense of dependence on their gymnastic identity that kept two of the gymnasts coming back year after year. In addition, the gymnasts' difficulties with balancing sport with academic and social demands, as well as the perceived contributing influence of perfectionism, pressures, expectations, frustration, and disappointment supported several findings that burnout can be caused by both sport and nonsport personal and situational factors (Cresswell \& Eklund, 2006; Gould et al., 1996a, 1996b, 1997; Gustafsson et al., 2007; Smith, 1986). In addition, much like the tennis players from Gould et al.'s work (1996b), two of the gymnasts demonstrated ineffective planning strategies and poor coping skills, thus increasing the risk of burnout. In addition, consistent with Gould et al.'s (1996b) research, the athletes in the current study emphasized the importance of friendship and teammates. The gymnasts explained that as they advanced in the sport, however, several teammates had either changed groups or left the gym, thus reducing friendship opportunities.

Despite the numerous parallels between the contributors highlighted within the current study and previous research, a few distinctions can also be noted. First, the present findings only minimally supported studies by Silva (1990) and Raedeke et al. (2002), where it was emphasized that burnout resulted from high training loads and the inability to cope with physical training demands. Herein, the gymnasts that scored highest on the Athlete Burnout Questionnaire (Raedeke \& Smith, 2001) seldom had the most intense training schedules. Although this finding is based on only three athletes and must be interpreted with caution, there are preliminary indications that, in some cases, intense physical training may not be the most noteworthy contributor to burnout. Also unlike findings suggested by Gould et al. (1996a, 1996b, 1997), the gymnasts did not generally encounter high parental expectations or pressure. Rather, parental influences were regarded as sources of support and motivation. Finally, the need for organization and the tendency to set 
low personal goals communicated by Gould et al. (1996a, 1996b, 1997), were not reflected by the gymnasts, who often lacked appropriate organizational skills and set ambitious goals. In fact, overly challenging goals may possibly be one of the reasons they had felt disappointed and frustrated.

Within the current study, burnout contributors were uncovered that did not emerge in previous literature. First, fearing potential injuries was listed by several respondents as perceived stressors for the athletes. In addition, it was shared that the failure to meet competitive goals could have contributed to the burnout of one of the gymnasts. Attempting to maintain a balance between school, gymnastics, and a social life, however, was a significant struggle acknowledged by all respondents. In fact, the inability to sustain this balance due to poor organizational skills or to an overload of activities was most frequently listed as the primary cause of the gymnasts' burnout. Finally, within the current study, there was a clear discrepancy concerning burnout recognition. While the athletes and coaches seemed able to describe the burnout condition in relation to others, few were able to identify early burnout indicators among the gymnasts. Of utmost importance is that although the lack of consensus and recognition may not directly contribute to burnout, the failure to identify early warning signs could prevent an early intervention, thus increasing the risk that burnout symptoms will worsen.

\section{Methodological Implications}

The current project was unique in several ways pertaining to methodology. First, gaining insight from athletes, parents, and coaches not only provided a more comprehensive understanding of burnout in youth sport, it also highlighted differing perspectives. For example, in two of the three cases, parents and coaches were unaware of many of the previous struggles communicated by the gymnasts. In addition, while parents and coaches spoke of understanding the burnout process and listed many associated symptoms, they did not detect the presence of the same symptoms when referring to the gymnasts in this study. Although, the current findings represent a very small participant group of three triads, they do invite future studies with larger sample sizes to substantiate the presence of these discrepancies, and if so, to determine why such discrepancies may exist within and across cases. It is proposed that through a triadic approach, case studies might lead to a deeper understanding (and a shared understanding) when discrepancies exist. In addition, the present work reflected the integration of a bracketing interview (see Rolls \& Relf, 2006), where the first author identified her biases and then attempted to suspend them through reflexive practices within and after the data collection. The integration of bracketing, beyond its salience for researchers, might also encourage reflexivity (i.e., self-awareness) among practitioners engaged in case studies, where multiple vantage points might also serve to bias the investigator/ practitioner. Finally, vignettes (see Spalding \& Phillips, 2007) in a hybrid format were also provided as part of the project, combining the objective description of snapshots with the personalized/authentic aspects of portraits. The salience of such vignettes as meta-narratives melded verified researcher analyses with anecdotes to enhance authenticity/depiction. 


\section{Limitations}

Despite its contributions to the burnout literature, the current study had limitations. First, the number of athlete participants was restricted due to the comprehensive approach taken to understand each athlete's unique case. Second, to select eligible gymnasts, the Athlete Burnout Questionnaire (Raedeke \& Smith, 2001) was administered. Although it has demonstrated satisfactory construct validity and reliability (see Cresswell \& Eklund, 2006, 2007; Lemyre, Treasure, \& Roberts, 2006), its validity has not been evaluated in relation to an adolescent population nor were the questions designed to be asked retrospectively, since it is intended to measure current levels of burnout. Next, while retrospective interviewing allows the participants to share past experiences, pertinent details from past experiences are more likely to be forgotten or to be cognitively reconstructed (Giorgi \& Giorgi, 2008). Nevertheless, Christianson and Safer (1996) suggested that recall of important emotional experiences such as burnout are less likely to be forgotten. Finally, the results from this study are limited to early and middle adolescent female gymnasts from one region. The current study was exploratory, and the challenges encountered by the gymnasts cannot be directly matched with those faced by adolescent athletes competing in different sports, nor could they be compared with gymnasts of different age groups or from various regions.

\section{Implications for Research and Practice}

Experiences shared in the current study provide insight for athletes, parents, coaches, and sport psychologists and researchers. First, the implementation of the bracketing interview, focus groups interviews, and the illustration of the findings through vignettes provide avenues worthy of consideration. The bracketing interview, for example, can create self-awareness among researchers and practitioners in terms of a priori biases. Next, through a triadic approach, seeing as though parents and coaches can be unaware of the gymnast's struggles, it becomes more likely for gymnasts to communicate with the coach and parent, perhaps leading to effective prevention strategies and more enjoyment and persistence in the sport. The triadic approach also offers researchers a comprehensive understanding of each burnout case as it arises, and also in retrospect. Follow-up communication among the athlete, parent, and coach would also provide an in-depth understanding of the athlete's experiences and the opportunity to become aware (quickly) of any changes in attitude or behavior. The tracking of communication would allow researchers, practitioners, and triads to work in tandem, leading to practical solutions. Finally, the sport psychologist can help prevent burnout by organizing workshops and presentations for parents, coaches, and athletes (together), providing information related to typical and atypical contributors, early warning signs, and adaptive coping strategies. Finally, within the workshops, each of the three types of vignettes holds clinical relevance. Snapshots can be employed for diagnostic purposes from the practitioner's arm's length perspective, with the analysis shared among the triad. Portraits can serve as exercises for each triad member, where personal vantages can be shared with other triad members. Finally, composites can be developed to explore possible solutions among triad members to potential problems, though learning would be based on hypothetical scenarios. The response from each triad 
might provide the stakeholders with indications of forthcoming challenges, opening the door to better practice.

\section{Conclusion}

The present study highlighted that the integration of parents', coaches', and athletes' perspectives can provide a more complete and in-depth understanding of the burnout experience. Clear discrepancies emerged among triad members in relation to the identification of possible challenges faced by the gymnasts, as well as in the participants' ability to recognize the presence of burnout related symptoms. In addition, despite the emergence of a few common symptoms and contributors, each gymnast's burnout experience was unique in relation to the causes of burnout, associated symptoms, and the progression of this condition, suggesting that cases should be examined through an individualized lens. Finally, future researchers in the field are encouraged to determine how parents, coaches, and athletes can work together to prevent burnout and to establish individualized coping mechanisms and interventions to overcome this condition.

\section{Endnote}

${ }^{1}$ A copy of the interview guide can be obtained by contacting the lead author.

\section{References}

Christianson, S.A., \& Safer, M.A. (1996). Emotional events and emotions in autobiographical memories. In D.C. Rubin (Ed.), Remembering our past: Studies in autobiographical memory (pp. 218-243). New York: Cambridge University Press.

Coakley, J. (1992). Burnout among adolescent athletes: A personal failure or social problem? Sociology of Sport Journal, 9, 271-285.

Cresswell, S.L., \& Eklund, R.C. (2006). The nature of player burnout in rugby: Key characteristics and attributions. Journal of Applied Sport Psychology, 18, 219-239.

Cresswell, S.L., \& Eklund, R.C. (2007). Athlete burnout: A longitudinal qualitative study. The Sport Psychologist, 21, 1-20.

Freudenberger, H.J. (1975). The staff burn-out syndrome in alternative institutions. Psychotherapy: Theory. Research and Practice, 12, 73-82.

Freudenberger, H.J., \& North, G. (1985). Women's burnout: How to spot it, how to reverse it, and how to prevent it. New York: Doubleday.

Gauthier, A.P., Schinke, R.J., \& Pickard, P. (2006). Coaching adaptation: Techniques learned and taught in one northern Canadian region. The Sport Psychologist, 20, 449-464.

Giorgi, A., \& Giorgi, B. (2008). Phenomenology. In J.A. Smith (Ed.), Qualitative psychology: A practical guide to research methods (pp. 26-52). Thousand Oaks, CA: Sage.

Goodger, K., Wolfenden, L., \& Lavallee, D. (2007). Symptoms and consequences associated with three dimensions of burnout in junior tennis players. International Journal of Sport Psychology, 38, 342-364.

Gould, D., \& Dieffenbach, K. (2002). Overtraining, underrecovery, and burnout in sport. In M. Kellermann (Ed.), Enhancing recovery: Preventing underperformance in athletes (pp. 25-35). Champaign, IL: Human Kinetics.

Gould, D., Tuffey, S., Udry, E., \& Loehr, J. (1996a). Burnout in competitive junior tennis players: II. Qualitative analysis. The Sport Psychologist, 10, 341-366. 
Gould, D., Tuffey, S., Udry, E., \& Loehr, J. (1996b). Burnout in competitive junior tennis players: A quantitative psychological assessment. The Sport Psychologist, 10, 322-340.

Gould, D., Tuffey, S., Udry, E., \& Loehr, J. (1997). Burnout in competitive junior tennis players: III. Individual differences in the burnout experience. The Sport Psychologist, $11,257-276$.

Gustafsson, H., Kenttä, G., Hassmén, P., \& Lundqvist, C. (2007a). Prevalence of burnout in competitive adolescent athletes. The Sport Psychologist, 21, 21-37.

Gustafsson, H., Kenttä, G., Hassmén, P., Lundqvist, C., \& Durand-Bush, N. (2007b). The process of burnout: A multiple case study of three elite endurance athletes. International Journal of Sport Psychology, 38, 388-416.

Gustafsson, H., Kenttä, G., Hassmén, P., \& Johanssone, M. (2008). A qualitative analysis of burnout in elite Swedish athletes. Psychology of Sport and Exercise, 9, 800-816.

Hampel, P., \& Petermann, F. (2006). Perceived stress, coping, and adjustment in adolescents. The Journal of Adolescent Health, 38, 409-415.

Hollander, D.B., \& Meyers, M.C. (1995). Psychological factors associated with overtraining: Implications for youth sport coaches. Journal of Sport Behavior, 18, 1-18.

Lemyre, P.N., Treasure, D.C., \& Roberts, G.C. (2006). Influence of variability in motivation and affect on elite athlete burnout susceptibility. Journal of Sport \& Exercise Psychology, 28, 32-48.

Maslach, C., \& Jackson, S.E. (1981). The Measurement of experienced burnout. Journal of Occupational Behaviour, 2, 99-113.

Maxwell, J.A. (2002). Understanding and validity in qualitative research. In A.M. Huberman \& M.B. Miles (Eds.), The qualitative researcher's companion (pp. 37-63). Thousand Oaks, CA: Sage Publications.

Meehan, H.L., Bull, S.J., Wood, D.M., \& James, D.V.B. (2004). The overtraining syndrome: A multicontextual assessment. The Sport Psychologist, 18, 154-171.

Morgan, D.L. (1997). Focus groups as qualitative research. In J.V. Maanen, P.K. Manning, \& M.L. Miller (Eds.), Qualitative research methods (Vol. 16, 2nd ed., pp. 1-80). Thousand Oaks, CA: Sage.

Patton, M.Q. (2002). Qualitative research and evaluation methods (3rd ed.). Thousand Oaks, CA: Sage.

Raedeke, T.D. (1997). Is athlete burnout more than just stress? A sport commitment perspective. Journal of Sport \& Exercise Psychology, 19, 396-417.

Raekeke, T.D., Lunney, K., \& Venables, K. (2002). Understanding athlete burnout: Coach perspectives. Journal of Sport Behavior, 25, 181-206.

Raedeke, T.D., \& Smith, R.E. (2001). Development and preliminary validation of an athlete burnout measure. Journal of Sport \& Exercise Psychology, 23, 281-306.

Rolls, L., \& Relf, M. (2006). Bracketing interviews: addressing methodological challenges in qualitative interviewing in bereavement and palliative care. Mortality, 11, 286-305.

Schinke, R.J., \& da Costa, J.L. (2000). Qualitative research in sport psychology. Avante, $6,38-45$.

Schmidt, G.W., \& Stein, G.L. (1991). Sport commitment: A model integrating enjoyment, dropout, and burnout. Journal of Sport and Exercise Psychology, 8, 254-265.

Silva, J.M. (1990). An analysis of the training stress syndrome in competitive athletics. Journal of Applied Sport Psychology, 2, 5-20.

Smith, R.E. (1986). Toward a cognitive-affective model of athletic burnout. Journal of Sport Psychology, 8, 36-50.

Spalding, N.J., \& Phillips, T. (2007). Exploring the use of vignettes: From validity to trustworthiness. Qualitative Health Research, 17, 954-962.

Tesch, R. (1990). Qualitative analysis types and software. New York: Falmer.

Urdan, T., \& Klein, S. (1998). Early adolescence: A review of literature. The. U.S. Department of Education: Office of Educational Research and Improvement. Retrieved May 5, 2007, from http://www.mprinc.com/pubs/pdf/early_adolescence.pdf. 